\title{
A CRÍTICA À SUPERSTIÇÃo NO PENSAMENTO DE PIERRE BAYLE
}

\section{Marcelo de Sant'Anna Alves Primo}

\begin{abstract}
Resumo: A superstição é definida por Bayle, em diversos momentos e diversas obras do filósofo francês, como: a) algo característico da corrupção natural humana; b) a prova da facilidade do homem em se ater às mais diversas crendices, logo, estando sujeito não só a uma, mas a todo tipo de superstiçōes; c) o fenômeno que se instaurou e se disseminou na sociedade, perseguindo a todos e gerando ilusóes por toda parte, através de presságios, profecias, prodígios, e sinais. Nesse quadro de diversas e intangíveis absurdidades, a superstição ganha forma, indo para além dos domínios da razão e, assim, Bayle, em seus escritos, torna manifesta a oposiçấo entre a filosofia e a ignorância supersticiosa, entre o entendimento e a imaginação e entre as explicaçôes científicas e os relatos fantásticos.
\end{abstract}

Palavras-Chave: Bayle. Crítica. Superstição.

"La superstition est manifestement l'expression d'une sorte de lâcheté visà-vis de la divinité.” (THÉOPHRASTE, Caractères, XVI).

\section{A DEFINIÇÃo DE SUPERSTIÇÁO}

Superstição é, por definição, a propensão do homem a atribuir razôes ocultas ou sobrenaturais a fatos explicáveis, ou possíveis de serem explicados por causas naturais. Em termos teológicos, significa toda crença e prática que vai de encontro com a própria religiáo - seja ela qual for - por meio de cultos, rituais privados, magias e toda sorte de devoçóes (ABBATE, 1993, p. 18) Quanto à etimologia, a palavra deriva do latim superstitio ${ }^{2}$, cuja origem era ignorada pelos antigos. O primeiro autor a usar o vocábulo superstição teria sido Cícero, em seu De natura deorum, relacionando-o à devoção

\footnotetext{
${ }^{1}$ Bolsista PNPD - CAPES/UFS, docente colaborador do Departamento de Filosofia e do Programa de Pós-Graduação em Filosofia da Universidade Federal de Sergipe. E-mail: marceloprimo_sp@hotmail. com

2 Sendo seu correspondente grego deisidaimonia, vocábulo que significa "temor a um deus", de deido, temor e daimon, divindade, temor que, em sua origem, excluía na deisidaimonìa a ideia de superstiçăo. Ver mais, a respeito do uso do termo por autores antigos, como Políbio e Aristóteles, por exemplo, no texto de Mario Scaffidi Abbate "Il fato e la superstizione". In: PLUTARCO. Il fato e la superstizione. Tradução de Mario Scaffidi Abbate. Roma: Tascabili Economici Newton, 1993, p. 18-19, em particular.
}

http://dx.doi.org/10.1590/S0101-31732017000300008 
excessiva nas oraçóes dos pais, para que seus filhos sobrevivessem, de sorte a fazer sacrifícios aos deuses, a fim de continuar a linhagem de superstição por seus filhos, dando assim um sentido mais amplo a esse termo. ${ }^{3}$ Nesse sentido, superstição torna-se tudo o que é "[...] estranho à pura racionalidade, como a fé nos milagres, no poder das imagens divinas, na sobrevivência individual após a morte, $[\ldots]$ como uma invenção para entreter o povo ignorante, o 'ópio do povo', e assim vai." (ABBATE, 1993, p. 19) A superstição também é a constatação de que, mesmo com a utilização de todos os meios para rebatêla - a experiência, a ciência, a reflexão crítica - visando a analisá-la e regulála, ainda permanecem alguns resquícios que são verdadeiros empecilhos a qualquer apreciação crítica em relação às origens, intenções e práticas supersticiosas, restando ainda o anseio de consentir a poderes ocultos do gênero de forças naturais e de apelar a receitas sobrenaturais, conforme a determinados interesses.

Recorrendo à história da filosofia, textos propriamente ditos sobre a superstição ou a crítica da mesma são poucos ou quase nulos. Há o texto de Plutarco, O fato e a superstiçáo, obra na qual o filósofo enfatiza que a superstição tem sua origem em uma interpretação errônea da divindade e das suas leis, causadora de paixóes desenfreadas que levam a práticas temerárias, e o supersticioso, por sua vez, seria uma figura antissocial, pois, sendo escravo de seus próprios temores, tende ao isolamento. ${ }^{4}$ Também há o verbete "superstição", dos Ensaios de Francis Bacon, no qual ele faz eco às teses de Plutarco - inclusive o cita - entendendo que as causas da superstição são os excessos dos cultos religiosos, os quais ocasionam uma confusão perniciosa entre assuntos divinos e humanos, ou tratar o que é humano como divino e vice-versa. E, da mesma forma, no "Prefácio" do seu Tratado teológico-politico, Espinosa afirma categoricamente que as duas fontes da superstição são o medo e a esperança, e os homens, na maioria das vezes, ora pendem para um, ora para outra. ${ }^{5}$ Nesse sentido, após toda a reflexão desses autores sobre o fenômeno supersticioso, examinaremos o que o próprio Bayle entende por superstição.

\footnotetext{
${ }^{3}$ Quanto à amplitude do termo, ver Askevis-Leherpeux (1988, p. 6): A superstiçẫo, devido ao "[...] seu caráter irracional, pode estender-se a outros domínios além do sacro."

${ }^{4}$ Bayle, nos $P D$, dedica o parágrafo $\$ 193$ para refletir sobre esse escrito de Plutarco.

5 Ver também os Caracteres, de Teofrasto. Precisamente no capítulo XVI, intitulado "O supersticioso", ele define a superstição. Esta é "[...] manifestamente a expressão de uma espécie de covardia diante da divindade." (THÉOPHRASTE, 2010, p. 51).
} 


\section{$2 \mathrm{O}$ FENÔMENO SUPERSTICIOSO N'O FATO E A SUPERSTIÇÃO DE PLUTARCO}

Primeiramente, vamos à obra de Plutarco. N'O fato e a superstição, o autor salienta que a ignorância e a estupidez do homem acerca da divindade se bifurcam em dois caminhos: o ateísmo e a superstição - " [...] em caracteres duros - como em um terreno árido - o ateísmo, a outra, em caracteres moles - como em um terreno úmido - a superstição." (PLUTARCO, 1993, p. 65). Erros de juízo em questôes dessa importância são um mal que pode tomar proporçóes inimagináveis, quando aí entra o sentimento, uma vez que este, podendo ser arrebatador, torna-se uma chaga ou mesmo uma doença: "[...] como a luxação de uma articulação a qual se acrescenta uma ferida, assim a distorção do ânimo acompanhada da paixão é ainda mais grave." (PLUTARCO, 1993, p. 65). Plutarco menciona que, se alguém cometesse o equívoco de defender que o princípio de todas as coisas fosse os átomos, por exemplo, em nada isso ocasionaria alguma ferida ou dor em alguém; entender que a riqueza é o bem mais precioso da vida, juízo o qual perturba a alma e que não dá um só momento de trégua, também seria um erro sem consequência concreta alguma; pensar que a virtude e o vício são de natureza corpórea ${ }^{6}$ é igualmente um equívoco, mas não merecedor de lamentaçóes (PLUTARCO, 1993, p. 65). Porém, compreender que a injustiça é a fonte das riquezas e que a licenciosidade é a matrona dos prazeres são opiniốes equivocadas, as quais “[...] merecem ao mesmo tempo indignação e piedade, porque geram no ânimo daquele que o cultiva inúmeras paixôes e males, símiles a vermes e larvas." (PLUTARCO, 1993, p. 65).

Plutarco põe na balança qual erro seria mais funesto: não crer em uma divindade ou cultuá-la sem escrúpulos, impulsionado pelas paixóes. Se o ateu tem uma falsa opinião de que não existe deus algum, em prol da sua falta de fé, "[...] parece conduzir a uma sorte de indiferença e crê-lo a ponto de que Deus não exista finda em não temê-lo." (PLUTARCO, 1993, p. 67). Contudo, o supersticioso é o que é contaminado pelas emoçôes, que lhe causam um temor que o destrói, "[...] enquanto se crê que Deus exista, mas que seja hostil e danoso.” (PLUTARCO, 1993, p. 67). Nesse sentido, ateísmo é sinônimo de

\footnotetext{
${ }^{6}$ Curioso Bayle ter deixado passar esse trecho, porque o próprio Plutarco já entendia que assuntos concernentes à moral - a virtude e o vício - não podem ser limitados à ordem do puramente corporal. Nesse sentido, náo procede a crítica do filósofo de Carla. Nos $P D$, ele afirma que Plutarco "[...] não entendeu bem a questâo nem raciocinou: porque não se trata de comparar o bem físico do ateísmo com o bem físico da superstição, trata-se de compará-los um com o outro em relação à moral." (BAYLE, 2007, p. 401) Ver também as referências de Bayle ao mesmo texto de Plutarco, na CPD, LXXVILXXVII e LXXXIV, e nas APD, VI em particular.
} 
impassibilidade perante os deuses, ao passo que superstição significa excitação e entrega aos impulsos mais extravagantes. A ignorância no ateu resume-se à negação de um ser benevolente; no supersticioso, a ignorância é a sua fé na hostilidade dos deuses. Desse paralelo, Plutarco salienta que "[...] o ateísmo é só um raciocínio distorcido, enquanto que a superstição é um estado de ânimo que nasce de um raciocínio errado." (PLUTARCO, 1993, p. 65.) Em poucas palavras, o ateísmo configura-se como uma atitude de frieza ou desinteresse em relação à existência de uma ou diversas divindades, porém, a superstiçáo é uma torrente de paixóes cegas, as quais sempre trazem consigo a desconfiança de que um bem seja, na verdade, um mal. O supersticioso é aquele que simultaneamente teme e se refugia em um deus, acolhe-o e o insulta, acolhe-o e o desaprova. O filósofo chega à conclusão de que o ateísmo não é responsável pelo surgimento da superstição, mas, ao contrário, é ela que dá margem para o surgimento de ateus, já que, "[...] enquanto esta [a superstição] tem fornecido ao ateísmo uma razão para nascer e em seguida, uma vez que aquele [o ateísmo] cresceu, é uma justificação, que se não é válida e bela, não é sem motivo." (PLUTARCO, 1993, p. 89).7

\section{A CONCEPÇÁO BACONIANA DE SUPERSTIÇÃo}

Francis Bacon, no seu curto verbete "superstição", dos Ensaios, seguindo o raciocínio de Plutarco, ressalta que, pesando ambas as opinióes, a saber, se é melhor negar ou não proferir opinião alguma sobre a existência de um deus ou ter uma concepção extravagante do que seja uma divindade, o filósofo britânico não hesita: "É melhor não ter opinião alguma de Deus, a ter opinião indigna dele. Pois um é incredulidade e o outro é insolência; e certamente superstição é ofensa a Deus." (BACON, 2007, p. 60). Aludindo a Plutarco, Bacon argumenta que seria melhor para um homem afirmar a inexistência de uma divindade do que ser acusado, por meio de cultos e rituais sangrentos, de ser injurioso para com os deuses. ${ }^{8} \mathrm{E}$, da mesma forma, empreende o paralelo

\footnotetext{
7 Contudo, ao final da obra, Plutarco afirma que há uma justa medida entre a superstição e o ateísmo, a saber, a verdadeira religiosidade. O filósofo assevera que não se pode fugir da superstição dando "saltos", ou seja, aderir diretamente ao ateísmo: "É assim, de fato, que ninguém, para se salvar da superstição, termine por cair em um ateísmo rígido e obstinado, saltando com um pulo a verdadeira religiosidade, que está no meio." (PLUTARCO, 1993, p. 93).

8 "Plutarco disse bem a esse propósito: seguramente (disse ele) preferiria que muitos grandes homens dissessem que não havia nenhum homem chamado Plutarco, a que dissessem que havia um Plutarco quem comia suas crianças assim que nasciam; como os poetas falam de Saturno. E como a insolência é maior a Deus, assim o perigo é maior aos homens." (BACON, 2007, p. 60)
} 
entre o ateísmo e a superstição: o primeiro tem todas as possibilidades de estar em consonância com a virtude e a reta razão. $\mathrm{O}$ ateu pode seguir estritamente as leis estatais, ser piedoso e solícito para com o próximo e gozar de uma boa reputação, ainda que seu modelo de conduta não tome por parâmetro preceitos religiosos. Contrariamente, a superstição é o que subverte a mente dos homens, instaurando seu reinado na coletividade e arruinando todo um corpo social e político. É o agente causador de toda sorte de balbúrdias dentre os Estados, que aniquila a paz e solapa na base qualquer chance de ordem e prosperidade. ${ }^{9}$ Daí Bacon infere: "E vemos que o tempo inclinado ao ateísmo (como o de Augusto César) era tempo de paz. Mas a superstição tem sido a confusão de muitos Estados, ao trazer novo primum mobile, a subverter todas as esferas do governo." (BACON, 2007, p. 60).

O detentor e fomentador máximo da superstição é o povo, pois, “[...] em toda superstição, os sábios seguem os tolos e os argumentos são postos em prática, numa ordem invertida." (BACON, 2007, p. 60). Segundo Bacon, no tempo dos escolásticos - ele cita mais especificamente o concílio de Trento -, estes elaboravam teorias físicas e astronômicas, supostamente descreviam os movimentos dos corpos celestes, visando a salvar suas teses, mesmo sabendo que tais teorias não tinham fundamento científico algum. Faziam giros de retórica, criavam teoremas ininteligíveis táo e somente com o objetivo de preservar as práticas eclesiásticas (BACON, 2007, p. 60). O filósofo inglês escalona as causas da superstição: ritos e cultos que aprazam aos devotos, fingimento em demasia, reverências desnecessárias e indevidas a tradiçóes obsoletas, artimanhas de eclesiásticos gananciosos, favorecimento sem limites de intençóes supostamente boas que são a porta de entrada de novidades concernentes à religiấo. Da mesma forma, "[...] tratar assuntos divinos como humanos, o que cria mistura de imaginaçóes; e por último, os tempos bárbaros, especialmente os ligados a calamidades e desastres." (BACON, 2007, p. 61). Bacon assinala que a superstição é deformadora, ou seja, ela distorce a religiáo, para poder se fazer passar por uma, degradando o que outrora era bom em obediências e execuçóes tacanhas e sem sentido. ${ }^{10}$

9 "O ateísmo deixa o homem aos sentidos, à filosofia, à piedade natural, às leis, à reputação; tudo que pode ser guia para uma virtude moral externa, ainda que não seja religiosa; mas a superstiçấo desmonta tudo, e ergue uma monarquia absoluta na mente dos homens. Então o ateísmo nunca perturbou Estados; porque faz os homens cautelosos de si, como se não olhassem além.” (BACON, 2007, p. 60).

10 "Superstiçấo sem véu é algo disforme, pois deforma um macaco para torná-lo parecido com um homem; assim a semelhança da superstiçấo e religião a torna mais deformada. E assim como a carne sadia é corrompida por vermes, boas formas e ordens degradam em várias observâncias mesquinhas." (BACON, 2007, p. 61). 
Bacon conclui - como Plutarco - que é necessário ter em consideração que, para evadir-se da superstição, não se pode rejeitar de todo as tradiçóes antigas, mas reter o que ainda há de bom, nas mesmas, e somente expelir o que há de pernicioso de uma determinada doutrina em termos práticos - e aqui, mais uma vez, Bacon critica o povo - "[...] cabendo então o cuidado (como se faz expurgo em doente) de não rejeitar o bom junto com o ruim, que é comumente feito quando o povo for o reformador." (BACON, 2007, p. 61). ${ }^{11}$

\section{ESPINOSA E A QUESTÃo DA SUPERSTIÇÁO NO TRATADO TEOLÓGICO-POLÍTICO}

Espinosa, no prefácio de seu Tratado teológico-político, alude ao que faz com que os homens estejam sempre sujeitos aos grilhôes da superstição: "Se os homens pudessem, em todas as circunstâncias, decidir pelo seguro ou se a fortuna se lhes mostrasse sempre favorável, jamais seriam vítimas da superstição." (ESPINOSA, 2003, p. 5). Logo no início da passagem, o filósofo, submetendo ao condicional o poder de decisão do homem pelo correto e o favorecimento da fortuna, em todos os momentos, constata que a dificuldade de se decidir sobre algo e a inconstância das benesses da fortuna fazem com que os homens fiquem às vezes temerosos ou às vezes confiantes, ou sejam tomados ao mesmo tempo tanto pelo medo como pela esperança. ${ }^{12}$ Não é difícil ver que a maioria dos homens, quando a fortuna conspira ao seu favor, supóemse detentores de um saber que não é de sua competência e jamais aceitam uma segunda opinião; mas, se estão em uma situação adversa e sem qualquer chance de superá-la, agarram-se a qualquer predicação, seja de quem for, e, por mais estúpida que seja, a veem como uma luz no fim do túnel (ESPINOSA,

\footnotetext{
${ }^{11}$ Todavia, é bom frisar que a mesma crítica destinada à superstição, Bacon não a poupa contra o ateísmo: "Os que negam Deus arruínam a nobreza do homem, porque inquestionavelmente o homem aparenta-se aos animais pelo corpo, e se não aparenta-se a Deus por sua alma, é um ser vil e miserável. $\mathrm{O}$ ateísmo destrói igualmente a grandeza da alma, e a elevação da natureza humana. [...] É porque o ateísmo, detestável em todos os aspectos, o é igualmente no que ele priva a natureza humana dos meios de se elevar acima da fraqueza humana." (BACON, 1979, p. 87).

${ }^{12}$ Espinosa menciona que a hesitação do homem faz com que ele fique com medo e esperança, ao mesmo tempo, porém, se está confiante, fica cheio de si e manifesta a sua arrogância: "Mas como se encontram freqüentemente perante tais dificuldades que não sabem que decisão hão de tomar, e como os incertos benefícios da fortuna que desenfreadamente cobiçam os fazem oscilar, a maioria das vezes, entre a esperança e o medo, estão sempre prontos a acreditar seja no que for: se têm dúvidas, deixamse levar com a maior das facilidades para aqui ou para ali; se hesitam, sobressaltados pela esperança e pelo medo simultaneamente, ainda é pior; porém se estão confiantes, ficam logo inchados de orgulhos e presunção. Julgo que toda a gente sabe que é assim, não obstante eu estar convicto de que a maioria dos homens se ignoram a si próprios." (ESPINOSA, 2003, p. 5).
} 
2003, p. 5). Sempre, por qualquer coisa mínima que ocorra, eis os medos e as esperanças alimentadas novamente em suas imaginaçóes, o temor de algo que é entendido como um anúncio de algo maléfico que acontecerá futuramente, ou alguma coisa que faça vir à memória uma boa lembrança e hiperbolizada pelo aguardo de algo bom que possa vir a acontecer, náo levando nunca em consideração a quantidade de vezes que não aconteceu nem uma coisa nem outra, a despeito das fixações dos homens. ${ }^{13} \mathrm{~A}$ obsessão em ver prodígios é a mesma em todos os tempos e lugares, e, da mesma forma, a tentativa de erradicá-los, ou ao menos minimizá-los com sacrifícios, oferendas e orações. Para Espinosa, ela é típica de homens "[...] submergidos na superstição e adversários da religiáo que inventam mil e uma coisas e interpretam a natureza da maneira mais extravagante, como se toda ela delirasse ao mesmo tempo em que eles." (ESPINOSA, 2003, p. 6). ${ }^{14}$ O delírio oriundo e característico dos supersticiosos a respeito dos fenômenos naturais é sinônimo de escravidão, uma vez que a torrente de paixóes avassaladoras é o móbil do anseio desmedido dos homens por benefícios improváveis, implorando aos céus por alguma dádiva, e "[...] os devaneios da imaginação, os sonhos e as extravagâncias infantis, parecem-lhes respostas divinas.” (ESPINOSA, 2003, p. 6).

Espinosa fornece o diagnóstico da superstição, a saber, o medo ${ }^{15}$ : "O medo é a causa que origina, conserva e alimenta a superstição.” (ESPINOSA, 2003, p. 6). Um exemplo de quanto o homem oscila em suas crenças supersticiosas é o de Alexandre, o qual só se tornara supersticioso quando temera por sua sorte e, obtendo êxito em uma disputa, logo deixou de lado a necessidade

13 "Depois, sempre por motivos insignificantes, voltam de novo a esperar melhores dias ou a temer desgraças ainda piores. Se acontece, quando estão com medo, qualquer coisa que lhes faz lembrar um bem ou um mal por que já passaram, julgam que é o prenúncio da felicidade ou da infelicidade e chamam-lhe, por isso, um presságio favorável ou funesto, apesar de já se terem enganado centenas de vezes." (ESPINOSA, 2003, p. 6).

${ }^{14}$ Espinosa aqui chega à mesma conclusão de Plutarco e Bacon, isto é, a superstiçâao é inimiga da verdadeira religiosidade. Cf. a nota de Diogo Pires Aurélio em relação à dificuldade e à necessidade de precisar a oposição feita pelo filósofo entre o que é a vera religio e a vana religio. Cf. mais a respeito, TT-P, p. 313, nota 3. Segundo Homero Santiago (2009, p. 188), "[...] todo dia a experiência sugere a incoerência do código supersticioso e, decorrentemente, das explicaçôes do mundo que a sustentam." $\mathrm{Na}$ mesma linha de raciocínio, Askevis-Leherpeux (1988, p. 32-33) afirma que a superstição é "[...] um meio de reduzir a angústia resultante seja de um sentimento de impotência, seja de um estado de incerteza: dando ao homem a ilusão de controlar os acontecimentos importantes de sua vida, ela permitir-lhe-ia adaptar-se ao seu meio físico e social."

${ }^{15}$ Cf. com Plutarco (1993, p. 67): "Só o medo [paura], sendo privado de coragem e de racionalidade une a irracionalidade à incapacidade de agir, de escapar e de encontrar uma via de saída: por isso chamam temor [timore] e assombro [spavento] o que ao mesmo tempo prende e perturba a alma." (grifo nosso). 
de consultar adivinhos. Todavia, logo depois, perante uma situação adversa, abandonado por seus aliados, vítima de motins de seus inimigos e ferido gravemente, recorrera a um amigo de confiança para, através de sacrifícios, investigar o decorrer dos acontecimentos futuros. ${ }^{16}$ Desse exemplo histórico, Espinosa infere que "[...] os homens só se deixam dominar pela superstição enquanto têm medo" (ESPINOSA, 2003, p. 7) e que é nos momentos em que o Estado se encontra em uma situação limite que os adivinhos, disseminando suas previsóes, obtêm tanto o controle absoluto do povo como fazem que os reis fiquem mais temerosos. Espinosa, mostrando a causa da superstição, chega a três constataçóes: 1) que "[...] todos os homens lhe estáo naturalmente sujeitos" (ESPINOSA, 2003, p.7), não valendo como justificativa que todos os homens têm mais ou menos uma ideia vaga do que seja uma divindade; 2) que a superstição "[...] deve ser variável e inconstante" (ESPINOSA, 2003, p. 7), à proporção da variabilidade e inconstância das ficçóes produzidas pela mente, as quais não têm correlato e regularidade alguma no âmbito da experiência; 3) que as paixões são enganadoras, isto é, são as que fazem com que sempre subsista a superstição, pois tais equívocos "[...] não provêm da razão, mas unicamente da paixão, e da paixão mais eficiente.” (ESPINOSA, 2003, p. 7).

Nesse sentido, todos os fatores acima citados não fazem somente que os homens se prendam a uma única superstição, mas se percam em inúmeras, devido ao vulgo sempre estar intranquilo, entretendo-lhe somente o que é novo e o que ainda náo o fez incorrer em erro, "[...] inconstância essa que tem sido a causa de inumeráveis tumultos e guerras atrozes.”(ESPINOSA, 2003, p. 7). Ao final do "Prefácio", Espinosa recomenda unicamente a leitura de sua obra ao "leitor filósofo", considerando a relevância e a serventia do assunto abordado, uma vez que espíritos mais afetados possam apressadamente censurá-la, ou sequer mesmo entendê-la. ${ }^{17} \mathrm{O}$ filósofo justifica o porquê dessa triagem de

\footnotetext{
16 "Se depois do que já dissemos, alguém quiser ainda exemplos, veja-se Alexandre, que só se tornou supersticioso e recorreu aos adivinhos quando, às portas de Susa, começou pela primeira vez a temer pela sua sorte (ver Q. Cúrcio, Livro V, \$7); assim que venceu Dario, desistiu logo de consultar os adivinhos e arúspices. Até o momento em que, uma vez mais aterrado pela adversidade, abandonado pelos bactrianos, atacado pelos citas e imobilizado devido a uma ferida, recaiu (como diz o mesmo Q. Cúrcio, Livro VII, \$7) na superstição, esse logro das mentes humanas e mandou Aristandro, em quem depositava uma confiança cega, explorar por meio de sacrificios a evolução futura dos acontecimentos." (ESPINOSA, 2003, p. 6-7, grifo do autor) Bayle utiliza o mesmo exemplo de Espinosa e, inclusive, a mesma fonte, Quinto Cúrcio. Cf. PD, $\$ 154$. Sobre a imagem de Alexandre no século XVII, Ver a respeito, GRELL (2004, p. 297-308). Sobre a imagem de Alexandre traçada por Bayle, ver, em particular, p. 301-302 e DHC, 1697, "Alexandre".

17 "É isso, leitor filósofo, o que submeto aqui à tua apreciação, na esperança de nấo ser mal acolhido, tendo em conta a importância e utilidade do tema, quer da obra, quer até de cada um dos capítulos.
} 
leitores de sua obra: primeiro, o preconceito enraizado nas mentes, obstáculo quase insuperável para uma leitura sóbria da obra. Em segundo lugar, e em um tom de certo pessimismo, que "[...] é impossível libertar o vulgo da superstição e do medo" (ESPINOSA, 2003, p. 14) e, finalmente, constatando que a única invariável em comum entre os homens é a obstinação, não é a razão que lhes serve de guia e juiz, porém, a sua propensão natural tanto ao encômio como à ignomínia. ${ }^{18}$

\section{A REFLEXÃo de BAYLE SOBRE A SUPERSTIÇÃo}

Segundo Hubert Bost (2006, p. 182) , desde a estada de Bayle em Sedan, o filósofo "[...] tinha um interesse particular pelas questóes da crença em geral, e pela superstição em particular", que o leva "[...] a uma reflexão que se volta às manifestaçóes mais diversas da crença.” (BOST, 2006, p. 182, grifo do autor). Quanto às contribuiçôes de Bayle na reflexão sobre a questão da superstição, na "Introdução" de seu artigo intitulado "Bayle et la superstition" (1998) Mckenna alude às definiçôes do que propriamente seja a superstição: sob um enfoque teológico, superstição comportaria uma interpretação da natureza de um deus e como ele deve ser cultuado, o que suscitaria um duplo problema, ao seu ver, isto é, no que uma determinada divindade se distinguiria das outras e no que os cultos também se diferenciariam. Nesse sentido, essa definição seria tautológica, pois “[...] a superstição seria a fé dos outros", a qual não permitiria "[...] apreender o ato psicológico pelo qual se persuade da verdade ou do erro." (MCKENNA, 1998, p. 1). Não seria possível distinguir o ato de fé, "[...] o ato de adesão 'ortodoxa' do ato de adesão heterodoxa." (MCKENNA, 1998, p. 1). Contra Bernard Dompnier, Mckenna sustenta que a associação entre atos de fé ortodoxos e superstição é obnubilada pela suposta clareza da definição teológica daquela, que é ligada ao dogma. Do século XVII ao século XVIII - Mckenna cita Baptiste Thiers e Pierre Le Brun -, ocorre

Tinha ainda mais coisas a dizer, mas não quero que este prefácio se alongue a ponto de parecer um volume, sobretudo porque julgo que o essencial é sobejamente conhecido dos filósofos. Quanto aos outros, náo tento sequer recomendar-lhes este tratado, pois nada me leva a esperar que ele, por qualquer razão, lhes possa agradar.”_(ESPINOSA, 2003, p. 14.)

${ }^{18}$ Mesmo Bayle e Espinosa sendo críticos agudos da superstiçấo, é conveniente ter em conta que a relação entre ambos "[...] está longe de ser unívoca. Analisando-a, é preciso considerar mais uma vez as restriçôes retóricas que sobrecarregam a escrita bayleana, sobretudo, quando se trata de examinar uma doutrina filosófica heterodoxa e contrária à opinião dominante." (MORI, 1999, p. 156). Entretanto, a crítica de Bayle é concernente ao suposto ateísmo de sistema de Espinosa, e não referente à sua crítica à superstiçấo. 
uma evolução do termo, agora a superstição ganhando uma definição cultural, traduzida pelo engajamento contra o fanatismo e evoluindo "[...] com a definição do estatuto da razão no domínio da fé." (MCKENNA, 1998, p. 1). O comentador entende que é com Voltaire que a denúncia da superstição alcança seu pico máximo, e a tolerância aparece como uma conquista das Lumières (MCKENNA, 1998, p. 1). ${ }^{19}$ Contudo, segundo McKenna, nesse debate, Bayle ocupa um lugar à parte no que concerne tanto à sua postura sobre o papel da razão na esfera religiosa como sobre sua postura sobre a tolerância. Perpassando pelas diversas obras do filósofo de Carla, o comentador mostra que, quando Bayle (1998, p. 1) denuncia a superstiçáo, ele o faz tendo como motes “[...] os princípios da razão e do bom senso." Tanto que o filósofo de Carla argumenta, através da evidência das razóes, para demolir o arsenal das crenças supersticiosas ${ }^{20}$, entretanto, de forma puramente não-sistemática, investigando minuciosamente fatos históricos que deem respaldo a suas teses. Mas o que importa é que o fio condutor da argumentação não se perde em momento algum, pois, por trás de suas digressôes, subjaz “[...] a evidência da razão, bastando-lhe mostrar a absurdidade de tal crença sob o crivo da razão para crer refutá-la e ridicularizá-la." (MCKENNA, 1998, p. 3). ${ }^{21}$

Todavia, faz-se necessário entender o que seria a superstição para o próprio Bayle. Precisar a definição bayleana de superstição é um trabalho difícil, já que, nos Pensées diverses, na Continuation e na Addition, o filósofo emprega o termo em diversas passagens dentre tais obras. ${ }^{22}$ Por exemplo, nos Pensées diverses, Bayle define-a como uma tendência natural dos homens a

\footnotetext{
19 Afirmação bastante problemática, pelo fato de a tolerância pregada por Voltaire ser restrita unicamente às seitas fanáticas. Contudo, se consultarmos as apreciaçôes do filósofo sobre os ateus - cf. o verbete "ateu, ateísmo", de seu Dicionário filosófico, a sua publicação do Testamento de Jean Meslier e as anotaçóes sobre $O$ Bom Senso, de Holbach, dentre outros exemplos -, veremos um outro Voltaire, táo dogmático e fervoroso quanto os padres de sua época.

${ }^{20}$ Cf., mais especificamente, nos $P D$ os parágrafos $\$ 3, \$ 9, \$ \$ 16-17, \$ 23$, $\$ 24$, $\$ 45$, e $\$ 79$.

${ }^{21}$ Entretanto, as conclusōes de Mckenna, em seu artigo, estão deveras longe das minhas: à esteira da tradiçấo francesa, o comentador, baseando-se em alguns trechos controversos da obra de Bayle, sugere que ele seja um fideísta, ou seja, no que é assunto de fé a razão não pode intervir e vice-versa. O autor defende que Bayle (1998, p. 10) conduz o leitor “[...] a uma contradiçấo grosseira: o fideísmo que permite salvar a fé destrói sua própria doutrina da tolerância, ou então o racionalismo moral que fundou a doutrina da tolerância funda também a denúncia do escândalo e da fé. Observemos também - na perspectiva que é a nossa neste seminário - que, pela mesma ocasião, o fideísmo destrói o critério racional que fundou a denúncia da superstição nos Pensées diverses como no Dictionnaire."

${ }^{22}$ Ver. nos $P D$, os parágrafos $\$ 31, \$ \$ 50-51, \$ 61$, $\$ \$ 66-69, \$ 73, \$ \$ 79-82, \$ \$ 89-90, \$ \$ 153-154, \$ 193$ e $\$ 238$, na C.P.D, III, XXVIII, XXXI-XXXII, XLVI, XLVIII-XLIX, L, LIII-LIV, LVII-LVIII, LXIV, LXXI, LXXVI-LXXVII, LXXXIV, LXXXVII, CIV, CVIII, CXXI e CXXXIII, e nas APD, III-VI.
} 
se subjugarem, porque a ela "[...] eles são inclinados naturalmente", sendo a superstição "[...] um germe de corrupção na alma do homem que pode ser muito bem comparado a um fogo ateado a um material combustível." (BAYLE, 2007, p. 464; OD III $[P D]$, p.144a.). ${ }^{23}$ Nas Additions, Bayle reafirma essa propensão inerente à constituição humana, pois, asseverando que "[...] o homem sendo naturalmente supersticioso" (OD III $[A P D]$, p.171b. $)^{24}$, ele ironicamente argumenta que assim não há perigo algum do surgimento do ateísmo dentre os homens, já que é fato "[...] o espírito do homem voltarse facilmente à superstição" (OD III $[A P D]$, p.170b. $)^{25}$ e não somente o indivíduo, mas povos inteiros têm "[...] a tendência natural à superstição." $(\underline{O D}$

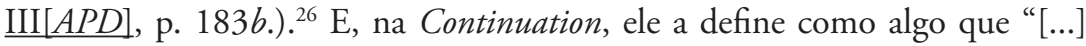
se apresenta por todos os lados para perturbar-nos e para perseguir-nos pelo grande número de presságios que ela introduziu.” (OD III [CPD] p. 235a $)^{27}$. Mas Bayle aprofunda mais a sua reflexão acerca do fenômeno da superstição, analisando-a em seus aspectos psicológico, político e pedagógico.

Nos Pensées diverses, Bayle reflete sobre um aspecto inerente à superstição, a saber, seu aspecto psicológico ou constituinte da natureza humana. Ironicamente, Bayle afirma que os demônios não encontrariam muitos obstáculos para levar os homens a alimentarem a ilusão de que há mistérios e prodígios em tudo que se encontre, já que a natureza do homem, "[...] é preciso confessar, para vergonha de nossa espécie, [...] ela tem uma

23 "Ce que je viens de dire de la superstition se doit entendre des autres vices. Il y a un germe de corruption dans l'âme de l'homme qui peut être fort bien comparé à un feu attaché à une matière combustible."

${ }_{24}$ "Ce paradoxe est incomparablement moins dangereux, que de dire que l'Idolâtrie Païenne est un moindre mal que le dogme d'Epicure; car l'homme étant naturellement superstitieux, il n'est point à craindre qu'il tombe dans l'Athéisme, mais il est toujours dans un pas glissant vers le culte des Idoles."

25 “Car dès-là que je suppose que l'on tourne aisement l'esprit de l'homme du côté de la superstition, $\&$ qu'il n'est nullement à craindre qu'on puisse le touner du côté de l'Athéisme, je supose de toute nécessité que l'esprit \& coeur de l'homme sont tout penetrez de l'idée de Divinité, \& que cette idée les remplit de crainte, $\&$ se conserve $\&$ se fortifie à la vue des productions de la Nature, $\&$ des merveilles de la Providence."

26 "Que vû le penchant des peuples vers la superstition, \& vigilance du Diable, celle des Magistrats \& celle des Prêtres à fomenter l'Idolâtrie, vû aussi les phénomenes peu communs que la providence de Dieu a mênagez dans la suite des loix générales de la Nature, il n’a pas été necéssaire de produire des miracles, afin de prévenir l'extinction de l'idolâtrie, \& l'introduction de l'Athéisme."

27 "Car elle se présente de tous côtez pour nous troubler, \& pour nous persécuter par le grand nombre de présages qu'elle a introduits.” 
tendência natural a isto.” (BAYLE, 2007, p. 161; OD III[PD], p. 436.) ${ }^{28} \mathrm{O}$ filósofo de Carla associa a superstição à corrupção inata e sempre em potência no homem, o qual somente espera algo que a faça eclodir e se propagar por todas as direçóes. Nesse sentido, se os astros celestes não são e nunca foram o estopim das paixôes humanas, não passam de meros espectros que são usados como depositários de vícios e ilusóes, destituídos de qualquer fundamento e atribuídos à fortuna, quando, na verdade, a sua origem reside na imprudência do homem. ${ }^{29}$ Bayle aponta para a confusáo deveras corriqueira entre o que é um prodígio e o que é natural. Argumenta que, por exemplo, se um animal gerar outro, sendo-lhe semelhante ou parecendo uma aberração, em nada isso deve ser entendido como um "desvio" do curso da natureza, porque "[...] o autor da natureza vai sempre seguir seu caminho e segue a lei geral que ele estabeleceu." (BAYLE, 2007, p. 162; OD III, p.44a.). ${ }^{30}$ A produção de um monstro é somente a manifestação da imutabilidade da ordem da lei que foi estabelecida, não sendo possível alterar a mesma para fazer milagres (BAYLE, 2007, p. 163; $O D \operatorname{III}[P D]$, p. $44 a$.). ${ }^{31}$ Dessa forma, se todas as manifestaçóes naturais são o resultado direto de uma ordem estabelecida - ou pré-estabelecida - por um suposto autor da natureza, o que interessa aqui é a conclusão de Bayle, isto é, desconhecendo as causas naturais dos fenômenos, o próprio povo se deixou levar por seus erros e, consequentemente, cair nas teias da superstição, "[...] vendo efeitos da natureza menos comuns do que outros." (BAYLE, 2007, p.

28 "Car il faut avouer, à la honte de notre espèce, qu'elle a un penchant naturel à cela." No parágrafo $\$ 238$, o raciocínio é o mesmo: "Eu repito o que já dissera antes no tocante à superstição: ainda que o diabo aí não tenha se imiscuído, os homens não deixaram de ceder, pois são inclinados naturalmente." [Je répète ce que j'ai déjà dit touchant la superstition: c'est qu'encore que le diable ne s'en fût pas mêlé, les hommes n'eussent pas laissé d'y tomber, tant ils y sont enclins naturellment."] (BAYLE, 2007, p. 463; $O D$ III $[P D]$, p. 144a, grifos meus).

29 "Mas, ao menos, é preciso que confessemos que os astros nấo são, de maneira alguma, a causa de nossas paixóes. São fantasmas, sobre os quais os homens se esforçam em descarregar as suas faltas com tão pouco fundamento como quando eles atribuem à fortuna os maus sucessos que só vêm de sua imprudência." ["Mais à tout le moins faut-il que nous avouions que les astres ne sont nullement la cause de nos passions. Ce sont des fantômes, sur lesquels les hommes tâchent de décharger leurs fautes avec aussi peu de fondement que lorsqu'ils attribuent à la fortune les mauvais succès qui ne viennent que de leur impriudence."(BAYLE, 2007, p. 464; OD III[PD], p.144b.)

30 "Ceux qui savent cela se tirent aisément d'affaire et voient bien que, soit qu'un animal produise un monstre, soit qu'il produise son semblable, l'auteur de la nature va toujours son grand chemin et suit la loi générale qu'il a établie."

${ }^{31}$ Argumento similar ao de Espinosa, em seu Tratado Teológico-Politico, cap. VI, intitulado "Dos milagres". Quanto às definiçôes e às críticas do milagre feitas por Bayle e Spinoza, cf. Jacqueline Lagrée (2004. p. 162-176). 
163; OD III $[P D], \mathrm{p} .44 a) .^{32}$

A forte propensão do homem para acreditar que os fenômenos naturais são avisos de maus infortúnios futuros é o fator determinante para que se fortaleça a crença de que há um mistério em todas as coisas e lugares. Assim sendo, é preciso que

[...] se considere a propensão natural do homem a se atormentar com o porvir e o costume que ele tem de encontrar o maravilhoso e o mistério em tudo que não acontece frequentemente. Esta insaciável curiosidade do porvir fez nascer não sei quantas maneiras de adivinhação, todas quiméricas e ridículas, as quais, entretanto, os homens não deixaram de comprar para si. Quando alguém foi bastante malicioso para querer aproveitar-se da fraqueza do homem e que teve bastante espírito para inventar alguma coisa que pudesse servir a esse desígnio, náo deixou de aí enganar, isto é, de tirar vantagem do conhecimento das coisas futuras. (BAYLE, 2007, p. 184; OD III $[P D]$, p. 51 b. $)^{33}$

Além da inclinação natural humana a crer que tudo que acontece de bom ou de ruim seja do âmbito do sobrenatural, Bayle ainda acrescenta três elementos para reforçar tal inclinação, a saber: a curiosidade de saber os acontecimentos futuros, móbil insaciável que possibilitou o surgimento de múltiplas formas de adivinhação, as quais, mesmo sendo vulgares e enganosas, sempre seduziram os mais crédulos; o costume bastante comum do homem em inquietar-se com seu próprio futuro, vivendo em função do que lhe predizem justamente por sua curiosidade; e o terceiro fator, mais grave, que é a malícia ou má-fé daqueles que se aproveitam da fragilidade dos homens, inventando previsôes e crendices sobre "[...] o que é, o que foi e o que será." (BAYLE, 2007, p. 185; OD III[PD], p.51b.). Nesse sentido, fica difícil aceitar uma interpretação reducionista dos Pensées diverses como um arsenal contra a superstição - mais especificamente, sobre os cometas - em prol da questão de

\footnotetext{
32 "Mais comme il faut de la philosophie pour s'elever à ces sortes de connaissances, je comprends aisément que le peuple se fût porté de lui-même à l'erreur et à la superstition en voyant des effets de la nature moins communs que les autres."

33 “[...] si l'on considère le penchant naturel de l'homme à se tourmenter pour l'avenir et la coutume qu'il a de trouver du merveilleux et du mystère dans tout ce qui n'arrive pas souvent. Cette insatiable curiosité de l'avenir a fait naître je ne sais combien de manières de divination, toutes chimériques et ridicules, dont néanmoins les hommes n'ont pas laissé de payer. Quand quelqu'un a été assez malicieuxpour vouloir profiter de la faiblesse de l'homme et qu'il a eu assez d'esprit pour inventer quelque chose qui pût servir à ce dessein, il n'a pas manqué de donner là-dedans, c'est-à-dire de se vanter de la connaissance des choses futures."
} 
saber somente quais autores ainda mantêm resquícios de superstição, em suas obras. ${ }^{34}$ Pelo contrário, Bayle se vale do episódio do cometa de 1680 como pretexto para a redação da obra, questão que ele vai desdobrar, investigando obras de autores - sejam físicos, historiadores e filósofos - e ver quais ainda sustentam que cometas ou quaisquer fenômenos naturais são sinais de mau agouro. Ou seja, se fosse tão óbvio entrever que a interpretação de eventos naturais não pode ser pautada por argumentos e critérios sobrenaturais, Bayle nem se daria o trabalho de escrever uma obra deveras exaustiva contra toda uma tradição de pensadores que ainda estavam, em grau maior ou menor, nas amarras da superstição. ${ }^{35}$

A segunda característica da superstição apontada por Bayle é a sua associaçáo com a política. Ele aborda mais detalhadamente a instrumentalização política da superstiçấo, isto é, como as autoridades de Estado se valem de determinados presságios para aterrorizar seus súditos ou para deixá-los confiantes (BAYLE, 2007, p. 186; OD III $[P D]$, p.52a.). ${ }^{36} \mathrm{Na}$ Continuation, ele assevera:

A superstição aí é tão excessiva, e de tal modo e propalada não somente sobre a conduta dos particulares, mas também sobre a conduta pública, [...] e eu penso que os Romanos fizeram isso por causa do povo. Porque se pudessem formar uma República onde houvesse somente pessoas sábias, todas essas cerimônias de religião seriam talvez supérfluas, mais visto que o povo é inconstante e cheio de paixôes injustas, que se irrita subitamente e que a cólera o leva à violência, só resta refreá-lo com terrores

\footnotetext{
${ }^{34}$ É o argumento de Eric Jorink. E o comentador vai mais além, afirmando que nem evidências empíricas, tampouco os debates filosóficos no tempo de Bayle serviriam para resolver as questôes científicas sobre o cometa, "[...] mas os virtualmente transparentes, até mesmo relevantes escritos da Antiguidade.” (2008, p. 57).

${ }^{35}$ Cf. o parágrafo $\$ 25$ dos $P D$, onde Bayle critica Jean Bodin, estabelecendo as premissas da questáo: a história é uma ciência investigativa de caráter empírico, logo, sendo contra toda espécie de relato supersticioso, que não permite ser recortada ou distorcida para servir de amparo a conclusóes tendenciosas e que repudia todo e qualquer preconceito ou pré-julgamento. Somente depois ele cita diversos exemplos, em meio a suas digressóes, de autores que ainda não conseguiram livrar-se do sobrenatural, em suas apreciaçóes sobre os fatos históricos, quer autores antigos, quer contemporâneos a Bayle. Ver igualmente CPD, CXVI.

36 "La politique s'est aussi mêlée du soin de faire valoir les présages afin d'avoir de bonnes ressources, ou pour intimider les sujets ou pour les remplir de confiance."
} 
invisíveis e com ficções assustadoras. (OD III [CPD], p.292ab.). ${ }^{37}$

Roma é somente um dos vários exemplos que Bayle cita de chefes políticos da Antiguidade, para mostrar o quanto fenômenos naturais, potencializados pelo seu terror pânico e crença desenfreada, alteraram seu temperamento, levando-os a hesitar em determinadas batalhas ou serem surpreendidos por motins de ordem política. ${ }^{38}$ Nesse sentido, para o filósofo francês, não é difícil constatar que "[...] as mesmas máximas de Estado que fomentaram a superstição dos povos a respeito dos outros prodígios também fomentaram a respeito dos cometas." (BAYLE, 2007, p. 188; OD III $[P D]$, p.52b.) ${ }^{39}$ E por quê? Por exemplo, se coincidisse o surgimento de um cometa nos céus com a vontade de uma determinada nação declarar guerra a algum reinado vizinho, ela levaria a cabo tal empreitada, movida pela predição de algum astrólogo de plantão, entendendo que esse episódio era uma ameaça ao príncipe. Contudo, tal postura não é privilégio unicamente dos grandes chefes de Estado. Segundo Bayle, os povos também têm sua parcela de contribuição no conúbio entre política e superstição, porque os homens veem naturalmente "[...] como presságios as menores coisas" (BAYLE, 2007, p. 190; $O D$ III $[P D]$ p. $53 a$. $)^{40}$, mas a política, por sua vez, escolheu os piores recursos para a prevençáo dos povos, visto que "[...] falsamente se imaginou que os cometas ameacem sobretudo os reis e os príncipes." (BAYLE, 2007, p. 190; $O D \operatorname{III}[P D]$, p. 53 a. $).{ }^{41}$

\section{A argumentação subjacente a essa constatação de utilização política}

\footnotetext{
37 "La superstition y est si outrée, \& tellement répandue non-seulement sur la conduite des particuliers, mais aussi sur la conduite publique, que l'on n'y sauroit rien ajouter, \& je pense que les Romains ont fait cela à cause du peuple.Car si l'on pouvoit former une République où il n'y eût que des gens sages, toutes ces cérémonies de religion seroient peut-être superflues, mais puisque le peuple est inconstant, $\&$ plein de passions injustes, qu'il s'irrite subitement, \& que la colère le pousse à la violence, il ne reste que de le réfréner par des terreurs invisibles, \& par sortes de fictions épouvantables."

${ }^{38}$ Cf., mais precisamente, o parágrafo $\$ 81$.

39 "Il est aisé de comprendre que les mêmes maximes d'État qui ont fomenté la superstition des peuples à l'égard des autres prodiges l'on aussi fomentée à l'égard des comètes."

40 "Mais si les grands ont contribué à faire croire que les comètes sont des présages de mauvais augure, les peuples y ont contribué aussi de leur côté: non seulement parce qu'ils se portent de leur naturel à traiter de présages les moindres choses, mais aussi par une certaine malignité qui les porte à s'imaginer facilement que ceux qui gouvernent ne s'en acquittent pas au contentement de Dieu."

41 "De sorte qu’il est arrivé enfin que la politique a trouvé de méchants côtés dans la prévention des peuples, parce qu’on s'est enfin faussement imaginé que les comètes menaçaient surtout les rois et les princes."
} 
tendenciosa de superstiçóes de todo tipo é que, na verdade, Bayle rebate a proposição de que o medo inculcado em uma determinada coletividade possa ser um freio para açôes que vão de encontro ao Estado. ${ }^{42} \mathrm{O}$ filósofo de Carla até concede que o medo seja um sentimento de amplo poder e ativo, mas discorda que seja um sentimento que faça com que os homens obtenham méritos, boas qualidades ou pensem antes de agir temerariamente (OD III $[C P D]$, p.375a.). Pelo contrário, o medo fez com que surgisse e se multiplicasse uma infinidade de cultos e sacrifícios, demolição de templos, oferendas e honrarias a ídolos, não servindo de nada para tornar os homens mais próximos dos deuses, e sim "[...] mais desagradáveis do que eles não tivessem reconhecido nenhuma Divindade." (OD III [CPD], p.375b-376a.)..$^{43}$ Nesse contexto, a consequência direta é o aumento dos crimes de lesa-majestade cometidos muito mais por supersticiosos do que por ateus, porque "[...] uma superstição é tão capaz de fazer obter um mau desígnio, por exemplo, o de alguns facciosos que conspiram contra a sua pátria, do que fazê-los fracassar." (OD III[CPD], p. 357 a.). ${ }^{44}$ Para Bayle, o fundamental é saber qual contribuição a superstição pode dar, no tocante à bondade e à prosperidade das naçôes, enquanto esta depender dos bons costumes. Todavia, é mínima, senão nula a sua contribuição, pois suas supostas utilidades somente são a resultante da "[...] destreza com a qual a política se faz prevalecer das superstições do vulgar." (OD III[CPD], p.376a.)..$^{45}$

A terceira faceta da superstição é o seu caráter pedagógico. $\mathrm{Na}$ Continuation, Bayle reflete acerca da dificuldade da diferenciação entre o que é oriundo da natureza e o que se é adquirido pela educação, porque, por

\footnotetext{
${ }^{42}$ Bayle ironiza com tal proposição: "Qual violência eles não cometem quando se trata de evitar um mal maior? Visto que os idólatras atribuíam a seus falsos Deuses a força de castigar neste mundo e no outro, e que eles os faziam mestres do raio, do granizo, das tempestades, da peste, da fome, dos tormentos do inferno, eles deviam em mil momentos determinarem-se ou a isso ou àquilo pelo medo da justiça divina. Logo, é um freio, uma espora que teria faltado a Ateus." [Quelle violence ne se sontils pas lorsqu'il s'agit d'éviter un plus grand mal? Puis donc que les Idolátres attribuoient à leurs faux Dieux la force de châtier $\&$ dans ce monde, $\&$ dans l'autre, $\&$ qu'ils les faissoient les maîtres de la foudre, de la grêle, des tempêtes, de la peste, $\&$ de la famine, $\&$ des tourments de l'enfer, ils devoient en mille rencontres se déterminer ou à ceci, ou à cela par la crainte de la justice divine. Or c'est un frein, c'est un éperon qui auroient manqué à des Athées."] (OD III[CPD], p. 3756.).

43 "Cela ne servoit de rien à rendre les hommes plus agréables à Dieu, \& les lui rendoit au contraire plus desagréables, que s’ils n'eussent reconnu aucune Divinité."

44 "Une superstition est aussi capable de faire réussir un mauvais dessin, celui par exemple de quelques factieux qui conspirent contre leur patrie, que de le faire échouer."

45 “Car pour ce qui est des utilitez dont la Religion n'est cause que par accident, \& qui n’en résultent que par l'adresse avec laquelle la Politique se fait prévaloir des superstitions du vulgaire, nous en parlerons plus à propos dans un autre lieu."
} 
exemplo, pode ser certo que todas as naçóes tiraram o dogma da existência de um deus através das impressóes da natureza, mas não através das impressões da educação, pois teria sido preciso em cada país estudar pormenorizadamente o estágio inicial da infância. Seria imprescindível

[...] aí ter observado os primeiros raios de luz que saem da alma das crianças e bem distinguir nelas o que precede a instruçáo do que é o seu resultado. Onde está o homem que tenha bastante lazer ou que viva o bastante para fazer todas essas experiências? (OD III[CPD], p.209a.). ${ }^{46}$

Diante dessa impossibilidade hercúlea de empreender uma análise de todas as fases da infância, em cada país, para poder discernir o que é propriamente da natureza e o que é fruto da educação, Bayle desenvolve o segundo movimento de sua argumentação: mesmo que fosse possível alguém precisar com exatidão o que é natural em uma criança e o que ela aprendeu pela educação, “[...] assegurar-se-ia que tivesse encontrado vestígios de religião nas crianças às quais jamais se falou que haja um Deus?” (OD III [CPD], p.209a. $)^{47}$ Isto é, já nos momentos iniciais da educação das crianças, o filósofo de Carla sustenta que a superstição vem junto ao processo, pois, desde o começo, "[...] é ordinariamente por aí que se começa a instruí-los, desde que elas sejam capazes de distinguir alguns sons e de balbuciar." $(O D D$ III $[C P D]$, p.209a.). ${ }^{48}$ Segundo o filósofo francês, esse é o maior obstáculo a esse tipo de pedagogia, para se poder saber, unicamente pelas impressóes da natureza, se uma criança chegaria a louvar um deus, já que sua crença está desde o berço moldada por influências externas, isto é, por influências não-naturais.

Bayle já descarta de antemão a infalibilidade dos instintos da natureza, sendo "[...] um princípio que me parece falso, para não dizer nada de pior." $\left(O D\right.$ III $[C P D]$, p. 220a.). ${ }^{49} \mathrm{O}$ equívoco do senso comum é somente entrever

\footnotetext{
46 "Il faudroit y avoir observé les premiers raïons de lumière qui sortent de l'âme des enfants, \& distinguer bien en eux ce qui précéde l'instruction d'avec ce qui n'est que la suite. Où est l'homme qui ait assez de loisir; ou qui vive assez pour faire tous ces expériences?”

${ }^{47}$ Voudriez-vous bien répondre, après y avoir bien pensé, qu'un homme qui les auroit faites exactement, assureroit qu'il auroit trouvé des vestiges de religion dans des enfants à qui l'on n'auroit jamais dit qu'il y a un Dieu?

48 'C'est ordinairement par là qu'on commence à les instruire, dès qu'ils sont capables de distinguer quelques sons \& de bégaïer."

49 "C'est un principe qui me semble fort douteux, pour ne rien dire de pis."
} 
defeitos nas crianças e não na própria natureza, visto que aqueles que as educam sempre constatam erros a serem corrigidos, seja através de promessas, seja de ameaças e boas instruçôes. Os progenitores, sendo incapazes de perceberem "[...] as faltas da Natureza, todos os filhos tornar-se-iam malandros e incapazes de nada valer em toda a sua vida." (OD III $[C P D]$, p. 220a.). ${ }^{50}$ Segundo Bayle, tanto o espírito como o coração das crianças estão em iguais condiçôes de fragilidade. Julgando todas as coisas somente por meio de seus sentidos, e não examinando o que lhes é transmitido por seus pares, elas assimilam facilmente crendices, fábulas, prodígios e toda sorte de superstiçóes. ${ }^{51}$ Esses embustes têm tanta capacidade de se instaurar nas mentes infantis que elas vêm a rejeitar tudo o que vá de encontro com suas concepçóes, como, por exemplo, o que seja um deus ou algum acontecimento natural, "[...] pois o que o povo crê, elas retêm por toda a sua vida.” (OD III $[C P D]$, p. 220a.). Entretanto, segundo Bayle, é mister abrir uma exceção a um minimum de pessoas que, através de um temperamento bom, de um gênio e razão acima da média, pela aplicação às ciências, "[...] corrigem as faltas da Natureza e se elevam dos preconceitos da infância. Somente se é um homem honesto e bem esclarecido quando se puder curar as doenças naturais da alma e seus efeitos." $(O D \text { III }[C P D], \text { p.220ab. })^{52}$

\footnotetext{
50 "Ceux qui les élevent trouvent toujours quelque vice à corriger, \& si par les menaces \& par les promesses, \& par de bonnes instructions, on ne réparoit les défauts de la Nature, tous les enfants deviendroient des garnements, \& incapables de rien valoir de toute leur vie."

51 "Eles creem cegamente em todos os relatos que lhes fazem: os contos da pele de burro, contos da carochinha, das fadas, as tradiçóes mais fabulosas, tudo o que sente o prodígio e o maravilhoso, as histórias romanescas agradam-lhes infinitamente que a simples e cândida verdade." ["Ils croïent aveuglèment tous les récits qu'on leur fait: les contes de peau d'âne, de ma mère l'oie, des fées, les traditions les plus fabuleuses, tout ce qui sent le prodige $\&$ le merveilleux, les histoires romanesques leur plaisent infiniment davantage que la simple \& le naïve vérité.”] (ibid.) E, no parágrafo XXV, Bayle afirma: "[...] estou certo que os filhos dos Cristãos receberiam sem nenhuma dificuldade a opiniáo que cada rio e cada montanha são Deuses, se lhes assegurasse isso na idade de 5 a 6 anos.” [“...je suis sûr que les enfants des Chrétiens recevroient sans aucune difficulté l'opinion que chaque rivière, \& chaque montagne sont des Dieux, si on le leur assûroit à l'âge de 5 ou 6 ans."] (p. 223a.).

52 "Exceptons un petit nombre de personnes qui par une superiorité de raison $\&$ de génie, ou par l'aplication aux sciences, ou par la faveur du ciel corrigent les défauts de la nature, \& se relevent des préjugez de l'enfance. On n'est honnête homme, \& bien éclairé, qu'autant qu'on a pû guérir les maladies naturelles de l'âme $\&$ leurs suites." Para um debate atual dos argumentos de Bayle acerca da nocividade da superstição em relação à pedagogia infantil, ver o livro do casal de argentinos ROZITCHNER; IANANTUONI (2008). Dentre os vários argumentos expostos pelos autores, um deles é a questão a respeito de saber o que tem de ser dito aos seus filhos, quando os mesmos lhes perguntam o que é um deus, já que eles tendo pais ateus, porém, o mundo que os cerca está longe de sê-lo. O cerne do argumento seria o pleno respeito à criança e a abertura de espaço para a sua opiniâo pessoal. Nesse sentido, Robert Paul Wolff afirma, em relação aos Estados Unidos: "Os indivíduos que se situam fora de qualquer grupo importante - digamos, os não-religiosos - são tratados como exceçóes e relegados, na prática, a um status de segunda classe. Os discordantes agnósticos por questão de consciência, por
} 
Nos Pensées diverses, Bayle assegura que uma educação recebida numa corte em nada previne os príncipes de incorrerem em comportamentos e atitudes supersticiosas. E também não é por que não levem à risca religiosamente tratados de paz, alianças com outras naçôes, ou privem suas paixôes de algo, que eles deixam de reconhecer um deus. ${ }^{53} \mathrm{E}$ Bayle vai mais além:

Eu o digo mais uma vez, os grandes do mundo são ordinariamente mais supersticiosos que os outros homens a respeito de certas coisas. Imagina-se que basta ser nascido em uma grande mansão e de ter sido educado na corte de um príncipe para ter um espírito grande e sublime. Mas os que imaginam isso confundem o espírito com o coração. (2007, p. 327; OD III[PD], p. 99a.). ${ }^{54}$

Inversão absoluta de valores empreendida por Bayle. Uma educação refinada não faz com que as grandes figuras políticas se libertem de suas superstições, pois suas atitudes, na prática, demonstram justamente o oposto. Se determinadas paixóes que estáo à prova de qualquer educação adquirida foram, no decorrer da história, o móbil das açóes políticas, logo, a superstição sempre estará presente nas cortes e reinos onde prevalece a polidez. É provável que um local privilegiado de nascimento e benefícios de uma educação polida possam elevar o coração, tornando alguns poucos indivíduos mais serenos, contudo, na maioria das vezes, eles se transformam em pessoas mais intrépidas e gananciosas. Todavia, segundo Bayle, o mesmo não se passa com o espírito. Ele frisa:

exemplo, são obrigados a servir nas Fôrças Armadas, enquanto aqueles que podem reivindicar até mesmo a base religiosa mais bizarra para a recusa são tratados com tolerância ritual e isentados pelos tribunais. Similarmente, os orfanatos são tão completamente dominados pelas três principais religióes que um casal religioso ou em que cada cônjuge tenha uma fé diferente não pode adotar uma criança em diversos Estados. O efeito líquido consiste em preservar a imagem oficial de três grandes religiốes na sociedade muito tempo depois de ter deixado ela de corresponder à realidade social e em desestimular o indivíduo a romper oficialmente os seus laços religiosos." (WOLFF,1970, p. 47-48).

53 "É então uma pura ilusão imaginar que, porque os príncipes que não observam religiosamente os tratados de paz, nem as alianças mais solenemente juradas, ou recusam alguma coisa a suas paixóes, eles não creiam que Deus não exista." [C’est donc une illusion toute pure de s'imaginer que, parce que les princes ne se font pas une religion d'observer les traités de paix, ni les alliances les plus solennement jurées, ou de refuser quelque chose à leurs passions, ils croient qu'il n'y a point de Dieu."] (BAYLE, 2007, p. 327; $O D$ III[PD], p. 99a.).

54 "Je le dis encore un coup, les grands du monde sont pour l'ordinaire plus superstitieux que les autres hommes à l'égard de certaines choses. On s'imagine qu'il suffit d'être né dans une grande maison et d'avoir un esprit grand et sublime. Mais ceux qui s'imaginent cela confondent l'esprit avec le coeur." 
Mas não ocorre do mesmo modo com o espírito. É preciso convir que ele é polido extremamente na corte; mas ele não adquire a grandeza, quero dizer, esta força que o eleva acima dos preconceitos da infância e que o póe em condição de penetrar até a origem da verdade através de mil erros os quais ela está ou coberta ou rodeada. (BAYLE, 2007, p.327; OD III[PD], p. 99a.). ${ }^{55}$

A superstição aqui se associa ao preconceito, mas, especificamente, aos preconceitos da infância, os quais impedem o espírito de chegar à verdade no emaranhado de erros em que ela está mergulhada. Essa "grandeza" que falta ao espírito só poderá ser adquirida uma vez que se ultrapassem e abandonem a todo custo os obstáculos impostos pela superstição, já que ser educado em um meio abastado e polido está longe de ser suficiente. Bayle conclui que a pompa de quem adquiriu um aprendizado em um meio polido e abastado não erradica preconceitos incutidos de longa data, no que concerne a preceitos religiosos e às verdades naturais. ${ }^{56}$ Nesse sentido, Bayle afirma que uma boa educação pode estar para além dos limites de uma corte, porque, "[...] se o ar do grande mundo curasse impressóes de religião que são comunicadas aos filhos, não veríamos tanta superstição como vimos nos primeiros homens da República romana." (BAYLE, 2007, p. 327-28; OD III $[P D]$, p. 99a). ${ }^{57}$

\footnotetext{
55 "Mais il n'en va pas de même de l'esprit. Il faut convenir qu'il se polit extrèmement à la cour; mais il n'y acquiert pas de la grandeur, je veux dire de cette force qui l'élève au-dessus des préjugés de l'enfance et qui le met en état de pénétrer jusqu'à la source de la vérité au travers de mille erreurs dont elle est ou couverte ou environnée."

56 "Assim, Senhor, convenhamos de boa fé que os grandes, com toda a pompa que os rodeia, não deixam de permanecer nos preconceitos da educaçáo tais quais os outros homens, seja a respeito dos dogmas de religiáo, seja a respeito das verdades naturais." ["Ainsi, Monsieur, convenons de bonne foi que les grands, avec toute la pompe qui les environne, ne laissent pas de demeurer dans les préjugés de l'éducation tout de même que les autres hommes, soit à l'égard des dogmes de la religion, soit à l'égard des vérités naturelles."] (BAYLE, 2007, p. 327; OD III[PD], p. 99a.).

57 "En effet, si l'air du grand monde guérrisait des impressions de religion que l'on communique aux enfants, nous ne verrions pas autant de superstition que nous en voyons dans les premiers hommes de la République romaine." No final do capítulo, Bayle, associando a superstição dos romanos à política dos mesmos, mostra que eles poderiam ser acusados de qualquer coisa, menos de serem ateus: "Parece, por uma infinidade de exemplos, que seus cônsules e seus ditadores, e pessoas semelhantes de primeira ordem, foram bastante supersticiosos. Os reis e os imperadores do paganismo o foram furiosamente, e poder-se-ia dar cem exemplos muito capazes de convencer que não era a política que agia, mas a doença do coração - ainda que eu confesse que é preciso frequentemente imputar sua superstição à sua política. [...] Um dos principais cúmplices de Catilina, a saber, Lentulo, engajou-se nessa conspiração porque imaginou que os livros das Sibilas e as respostas dos haruspícios prometiam-lhe o império de Roma: prova evidente que ele estava bem afastado do ateísmo, visto que ainda não reconhecera a vaidade dos augúrios." ["Il paraît par une infinité d'exemples que ses consuls et ses dictateurs, er semblables
} 
Uma educação ainda presa aos grilhôes da superstição fica reduzida aos preconceitos adquiridos de longa data, não podendo avançar no que concerne ao esclarecimento das origens dos fenômenos naturais e dos móbiles das açóes humanas. A insuficiência de uma educação adquirida em um meio que proporcione tudo o que seja necessário para elevar-se espiritualmente é ainda um entrave para uma sólida pedagogia, pois a superstição aí está imiscuída. $\mathrm{O}$ futuro príncipe não passará de um carola, estando submetido tanto às suas crendices como às crendices de quem o cerca. E a consequência fatal será a tomada de decisóes políticas, as quais, longe de levar em conta a dinâmica dos acontecimentos concretos, serâo motivadas por superstiçóes que, na maioria das vezes, não têm correspondência na prática.

\section{CONSIDERAÇÓES FINAIS}

Quando Bayle se defronta com o fenômeno supersticioso, consegue entrever o quanto ainda a superstição tem lugar no imaginário e nas açôes dos homens. Ao remetermos a discussão à Antiguidade, com Teofrasto e Plutarco, chegando a autores modernos, como Bacon e Espinosa, tivemos a intenção de reconstruir o conceito de superstição no decorrer da história da filosofia, visto que não há ainda um estudo específico que mapeie e situe em que momento determinados autores a tomaram como objeto de reflexão. Particularmente no pensamento de Bayle, a superstição ganha uma conotação deveras negativa, pois o supersticioso é aquele que ainda insiste em atribuir causas naturais a acontecimentos de caráter eminentemente natural. Influenciado e ao mesmo tempo distanciando-se dos autores que trouxemos aqui à tona, em todos os seus escritos, Bayle não dá margem para dúvidas, quando vê a superstição como um retrocesso para o saber filosófico, científico e histórico, como atenta para a sua periculosidade, quando imiscuída na ordem das coisas mundanas, interferindo nos pensamentos e nas decisôes dos homens. A reflexão bayleana sobre a superstição está longe de ser um resultado limitado do seu suposto fideísmo de origem protestante. Possui um cunho mais abrangente e consistente, não se limitando à oposição entre fé e razão, mas é levada para

personnes du premier ordre, ont été fort superstitieux, Les rois et les empereurs du paganisme l'ont été furieusement, et l'on en pourrait donner cent exemples très capables de convaincre que ce n'était pas la politique qui agissait, mais la maladie du coeur - quoique j'avoue qu'il faut imputer souvent leur superstition à leur politique." [...] L'un des principaux complices de Catilina, savoir Lentulus, s'engagea dans cette conspiration à cause qu'il s'imagina que les Livres des Sybilles et les réponses des haruspices lui promettaient l'empire de Rome: preuve évidente qu'il était bien éloigné de l'athéisme puisqu'il n'en était pas encore à reconnaître la vanité des augures."] (BAYLE, 2007, p. 328; OD III[PD], 996.). 
diversos campos do saber, como o da psicologia, o da educação e o da política, por exemplo. Denunciando a superstição não somente no âmago do senso comum, porém, entre aqueles que deveriam denunciá-la, Bayle a delineia como um móbil que, mesmo não levando em conta que determinadas crenças não tenham correlato respectivo algum na realidade, tem uma grande eficácia psicológica, política e social.

PRIMO, Marcelo de Sant'Anna Alves. The critique of superstition in Pierre Bayle's thought. Tans/form/ação, Marília, v. 40, n. 3, p.133-156, Jul./Set., 2017.

\begin{abstract}
Superstition is defined by Bayle at various times and in various works as: a) something characteristic of natural human corruption; b) proof of the ease of man in adhering to the most diverse beliefs, being subject not only to one but to all kinds of superstitions; c) a phenomenon which arose and spread in society, following everyone and creating illusions everywhere by means of omens, prophecies, miracles, and signs. In this context of the diverse and intangible absurdities in which superstition takes shape, going beyond the realms of reason, Bayle in his writings makes manifest the opposition between philosophy and superstitious ignorance, between understanding and imagination, and between scientific explanations and fantastic tales.
\end{abstract}

Keywords: Bayle. Criticism. Superstition.

\title{
REFERÊNCIAS
}

ABBATE, M. S. Il fato e la superstizione. In: PLUTARCO. Il fato e la superstizione. Tradução de Mario Scaffidi Abbate. Roma: Tascabili Economici Newton, 1993.

ASKEVIS-LEHERPEUX, F. La superstition. Paris: PUF, 1988 (“Que sais-je?”).

BACON, F. Essays. Traduction par Maurice Castelain. Paris: Aubier Montaigne, 1979 (Aubier Collection Bilingue).

. Ensaios. Tradução de Alan Neil Ditchfield. Petrópolis: Vozes, 2007.

BAYLE, P. Euvres diverses. La Haye: Compagnie des Librairies, 1737. 4 Tomes. [Paris: Hachette BnF, 2012]. 2007.

. Pensées diverses sur la comète. Édition Hubert et Joyce Bost. Paris: Flammarion,

DELPLA, I.; ROBERT, P. La raison corrosive: études sur la pensée critique de Pierre Bayle. Paris: Honoré Champion, 2003.

ESPINOSA, B. Tratado teológico-politico. Tradução de Diogo Pires Aurélio. São Paulo: Martins Fontes, 2003. 
GRELL, C. Alexandre le Grand au XVIIe siècle. In: Métis: anthropologie des monds grecs anciens. Paris; Athènes: Daedalus; Editions Ehess, 2004. p. 297-308.

LAGRÉE, J. Spinoza et le débat religieux. Rennes: Presses Universitaires, 2004.

MCKENNA, A. Pierre Bayle et la superstition. In: DOMPNIER, B. La superstition à l'âge des Lumières. Paris: Honoré Champion, 1998.

MORI, G. Bayle philosophe. Paris: Honoré Champion, 1999.

PLUTARCO, Il fato e la superstizione. Tradução de Mario Scaffidi Abbate. Roma: Tascabili Economici Newton, 1993.

ROZITCHNER, A.; IANANTUONI, X. Filhos sem deus: ensinando à criança um estilo ateu de viver. Tradução de Teodora Freire. São Paulo: Martins Fontes, 2008.

SANTIAGO, H. "Superstição e ordem moral no mundo". In: MARTINS, A. (Org.). O mais potente dos afetos: Spinoza e Nietzsche. São Paulo: Martins Fontes, 2009. p. 171-212.

THÉOPHRASTE. Caractères. Tradução de Nicolas Waquet. Paris: Payot \& Rivages, 2010.

WOLFF, R. P. Além da tolerância. In: MARCUSE, H.; WOLFF, R. P.; MOORE JUNIOR, B. Crítica da tolerância pura. Tradução de Ruy Jungmann. Rio de Janeiro: Zahar, 1970. p. 47-48.

Recebido em 18/08/2015

Aceito em 13/11/2016 
PRIMO, M. S. A. 